\title{
Study on Humanized Teaching Management System
}

\author{
Fang Wang ${ }^{1}$ \\ ${ }^{1}$ Armed Police Academy, Chengdu, Sichuan, 610213 \\ 65289031@163.com
}

Keywords: Education; Humanization; Teaching Management System

\begin{abstract}
Today's era is an explosion of knowledge, information networking, political multi-polarization and economic globalization era, in an era of college students seem more assertive personality, self-awareness is growing. Traditional indoctrination or mandatory approach to management of higher education to the "tube, card, press" characterized the situation can not meet the needs of development, China's higher education needs new thinking and depth of thought, the need to improve the quality and state of upgrade, need a cultural transformation and system innovation. The times call for more humane Higher Education Management System. Higher Education Management System in humanity, not only pay attention to the institutionalization of rationality into the base, but with particular emphasis on respect for the personality of college students, college students play potential, and create a more harmonious atmosphere relaxed managed to mobilize university students and teachers initiative and creativity.
\end{abstract}

\section{Introduction}

Higher Education Management System in order to coordinate and stable education, to stimulate creativity and maintain education body, to ensure the quality of education, an important way to improve management efficiency and security, is an important part of the modern university construction, but also to cultivate and foster a large number of people to adapt to social and economic development an important guarantee required. China's current education management system, generally traditional Chinese culture, "54" New Education in 1949 after the new Chinese education and practice three such heritage? Product. Such a regime pursues extreme scientism, utilitarianism, the only science and engineering education, the only intellectual supremacy, refined professional, discipline, implementation of elite education, special training to all the resources experts to nationwide power boost to a specific technology; as This shall eliminate most, layer selection of exam-oriented education, organizational injection, chalk and talk, rote exam. Disregard education and improve the overall quality of personality humanistic culture, ignoring basic civic and moral education in life, civic rights and obligations, integrity of the law and so on, blindly proclaim empty ideals, overstating the heroes and role models. Teaching, teaching materials are prominent political and ideological education bureaucratic, politicized. The end result is far from humane, neglect to teach and be taught by the initiative and creativity. As China's economic and social transition gradually from agricultural civilization to industrial civilization, establishing a socialist market economic system, the university management system will also be facing major changes, mainly in the development of educational management system are beyond the traditional confines of the old planned economy, implemented by the compulsory education management system in the traditional sense to to promote the comprehensive development of man is characterized by change, but an important change which is in the development of the management system more humane consideration to the issue, and tried to reform Existing education management system so that the content is more humane. In the current market economy, Higher Education Management System also allows colleges and universities to become socially oriented independent school entities, this requires colleges and universities need to continue to analyze, understand the social needs and market changes, independently developed educational goals, find themselves in competition coordinates, seek opportunities for their own development. Universities and reform the fee system under the market economy system, students and parents to bear the higher costs of a certain number of access to services and the formation of a service relationship between students 
and universities, which enable students to become the school's relationship with more active, which also requires education management to a more prominent position in the student body.

\section{Meaning and Status of Higher Education Management System}

Management originated in the common labor of mankind since ancient times already exists. Management is in a particular environment, a particular organization has resources for effective planning, organization, leadership and control, in order to achieve the stated objectives of the organization process. It includes four meanings: (1) management is to achieve organizational goals while intending to conduct the process; function (2) management can be divided into planning, organizing, leading and control of four parts, the basic functions of management; (3) management The validity of that full use of various resources, with minimal consumption to achieve organizational correctly. Organizational resources including human, financial, material, information, time, etc., management should include the coordination of activities undertaken to accomplish goals and human and material resources. (4) management under certain environmental conditions exhibition, 'and maintain dynamic equilibrium with the external environment.

Education as a planned development and training of human activity, it requires rigorous planning to carry out a planned and systematic, that is, the need to establish and improve education management system. Higher Education Management System as a system, at the level of the sequence, the functions have diversity. Higher Education Management System in the narrow sense refers specifically to regulate the teaching process and achieve the goal of teaching and the development of system management methods; generalized Higher Education Management System is functioning education and higher education to achieve the purpose of service of all rules and regulations and other legal requirements It is a social change with the times and continue to develop and update the system. We can say that teaching management is the main part of education management. Higher Education Management generally include teaching plan management, operation and management of teaching, education quality assessment, as well as discipline settings, select and creativity, style construction and supervision, teachers and educational philosophy of the update and other construction curriculum, educational materials and educational places infrastructure management, its basic task is to study the characteristics and operation of the process of higher education law, guarantee to carry out education activities, improve work effectiveness of higher education, improve the management of higher education and research and organize the implementation of education reforms. Namely the reform and development of higher education system through reform and development to achieve, and the formation process of development of higher education management system itself is constantly changing to adapt to the process of higher education needs of the community.

\section{Humanized Analysis of Higher Education Management System}

Humane education should be a new concept of modern education, it advocates the elements of education, the teaching process to follow human nature. Humane education targeting students of humane education. Stick to the "people-centered" Value Orientation essentially humane education, is to follow the law of development of people, people into their human education, is a comprehensive one person to know, love, Italy, and other fine 神 visible and physiological visible unity. Important representatives of the Frankfurt School Fromm claimed that human nature is a particular potential. People with personality potential and continue to better ourselves animals. "One thing is the human subject, which is equal to it is the human potential." Although born of human potential is innate, but acquired plays a role in the activation and development. Education is a special point to human practice, is a purpose to cultivate human social activities. No discussion of education which era where humanity hypothesis is not its logical premise of their era, so you can say a priori view of human nature determines the Education. "Noble and valuable point is that man: he was able to discover and understand their nature, and appropriate education can pursue Lixiangzhiguang guide people in the dark." Education humane education is a human respect, which 
focuses on stimulating and tap the potential of educated, people continue to achieve self-transcendence, and then the full realization of the self, is a view of human nature to meet the era of education. Today "humane education has two levels: the lowest level required to achieve education 'two no', that school education is no swearing, no threats, no corporal punishment, which is the minimum requirement, do the 'three no? The education of middle-level education impersonal, asked to do 'three have? that student teachers have a smile, caring, affection, this is the condition of education has the charm of humanity, can not do' three have 'education is lack of humanity, human education highest level, requires teachers should fully meet the reasonable needs of students, to fully develop the potential of students, the full realization of personality development of students, the lack of such ideals of education, it is the 'ought humanity' ( ideal humanity) completely let located in the 'practical humanity? (real humanity) of inhuman faith education. "Education is the concept of humanity from the people's needs, respect for human needs, including physiological, safety, social, mutual respect, Self potential to play other needs. Education humane specific requirements are: for the development of each of the educational system, to each specific educational actions necessary to meet the economic, political and cultural requirements, more importantly, whether you want to comply with human nature as a yardstick to measure, measure of value only when humanity rises necessary for the evaluation of educational activities inherent basis, the concept of humanity education of humanity with increasing education levels and get sublimated to become possible.

\section{Establish Humane Higher Education Management System Strategies}

From the current situation of education in our country, we are still in the transition period, the universities there is a very serious utilitarian tendencies. People on education requirements and awareness, mostly from a utilitarian point of view, always hope that people linked to career and life, while ignoring the teachers cultivate the human spirit, but also ignores the overall development of personality; social and school knowledge The requirements are also reflected in the concentrated practical value, thus making universities emphasis on science education, contempt humanistic education, focusing on intelligence than Germany's phenomenon, and education emphasizes teaching functions do not coincide. This is also caused by the rigidity of University policy. Thus, in establishing compliance with humane education management process requires managers to formulate flexible higher education policy, the establishment of education in society, subjectivity, human subjectivity status in education, so that education from a state of dependency and subordination, out of control and monopoly by the state, it was given the status of a strong national utilitarian value. In order to weaken the students' utilitarian thinking, deepen humanity.

Teachers and Higher Education Management System in "harmony", the main requirements in the overall penetration of the rapid development of modern science and technology and society at the same time, science and technology has gradually become the core driving force for social development. In this instrumental rationality, science and technology-oriented background, the school became a place for culture standardization talents. Also for the training of school management standardization of personnel continue to prepare. Goal of education has turned into a fast train a large number of labor force, in order to adapt to the needs of society. Therefore, the goal of school education has become standardized for cultivating talent, so contrary to human nature, it is the people into a machine, and even become a part of the machine, only to fulfill the functions of technical operations and disrupting people's values. This section allows students to understand and be able to understand their own created world. Only just saw the people instrumental value in development of science and art, but did not see the value of human subjectivity in science and technology development. Therefore, in the construction of university education management system, we can not get into this system management completely according to social demands, while ignoring the teachers in the boot of this process and for personnel training and dominant.

Highly uniform and highly centralized planned economy to a centralized university management has brought a variety of drawbacks, in a highly centralized planned economy and political system, management and control by the state universities here, including the purpose and policy of 
education, universities setting higher education system, the scope of activities and management authority, resource allocation, etc., university autonomy is quite limited, arrangements have to obey all the country. In the management system, the government department in charge of education in universities and a series of rules and regulations to carry out the management of universities, colleges and universities have been working Yiqin various administrative rules and regulations restraint, leaving universities to manage their own space too. Because of the current political system resulted in Higher Education Universities centralized management system is not in line with human development, visible, university itself is the reform and innovation, established in line with the main body of Higher Education Management System in the school science practical and social needs. With the changing times, but also the right school, university independent colleges and universities to establish education management system in line with its own characteristics is a historical necessity.

\section{Conclusion}

Change is the main characteristic of our environment. Higher education in recent years have made great progress in all aspects of higher education institutions in terms of both the number and size of tremendous growth. However, the complex changes in Chinese society-such as China's accession to WTO, widening intensified globalization, China's market-oriented society, the process of industrialization, the social structure, the impact of Western culture, the wealth gap and severe corruption phenomena, etc. - are significantly affecting the cultivation objectives, educational value and the quality of university education. These changes determine the university's mission to bring a new way of thinking. In the case of science and technology to accelerate development, the university assumed greater responsibility in social development. Chinese higher education is an urgent need to update the concept and system innovation.

\section{References}

[1] Li Teng. Educational University Teaching Humane Management. Technology Wind .2011 (12): 255.

[2] Si Cui. Students in Vocational Colleges Old Scholar of Management Humane Education. Vocational and Technical, 2010 (9): 93.

[3] Chen Yunian. Study on College Adult Education Humane Management. Yangtze University, 2008 (6): 324-325.

[4] Qin Xiaoyun. Research Ocean University of China, 2007 Issue of University Teaching Humane Management System: 104.

[5] Wei Qiaoyan, Li Ruigui. University Teaching Management Problems of Humanity Higher .2009 (6): 32. 